\title{
Polymorphisms rs1800795 of interleukin-6 and rs2228145 of interleukin-6 receptor genes in Euro- Brazilians with adult-onset type 1 diabetes mellitus
}

\author{
L.P. Campos ${ }^{1}$, V. Graciolo ${ }^{1}$, M.M. Sousa ${ }^{1}$, B.R. Martins ${ }^{1}$, S.W. Souza ${ }^{1}$, \\ D. Alberton ${ }^{1,2}$, G. Picheth ${ }^{1,2}$ and F.G.M. Rego ${ }^{1,2}$ \\ ${ }^{1}$ Programa de Pós-graduação em Ciências Farmacêuticas, Universidade \\ Federal do Paraná, Curitiba, PR, Brasil \\ ${ }^{2}$ Departamento de Análises Clínicas, Universidade Federal do Paraná, \\ Curitiba, PR, Brasil \\ Corresponding author: F.G.M. Rego \\ E-mail: rego@ufpr.br \\ Genet. Mol. Res. 18 (3): gmr18260 \\ Received February 02, 2019 \\ Accepted July 22, 2019 \\ Published July 26, 2019 \\ DOI http://dx.doi.org/10.4238/gmr18260
}

ABSTRACT. Type 1 Diabetes mellitus (T1D) is caused by the
immune-mediated destruction of insulin-producing islet $\beta$ cells, and
its pathogenesis involves cytokines. Genetic background may
influence cytokine signals, and polymorphisms may determine their
impact on T1D autoimmunity. Several polymorphisms in and close to
Interleukin-6 (IL-6) and Interleukin-6 Receptor (IL-6R) have been
identified as associated with pathological processes. We investigated
the IL-6 promoter -174G>C (rs1800795) and IL-6R Asp358Ala
(rs2228145) polymorphisms in 141 Euro-Brazilian patients with
adult-onset type 1 diabetes (diagnosis $>18$ years old) and 150 healthy
controls, matched by gender and age. Genotyping for both
polymorphisms was performed by PCR-RFLP. PCR fragments for
rs1800795 with Hsp92II and rs1800795 with HindIII were resolved
by $15 \%$ polyacrylamide gel electrophoresis. The polymorphisms in
both groups were in Hardy-Weinberg equilibrium. IL-6 rs1800795
was not different between healthy controls and T1D subjects,
showing $27.3 \%$ (95\% CI, $20-35 \%$ ) and $30.1 \%$ ( $23-38 \%$ ) for the C
minor allele (-174C), respectively. For IL-6R rs 2228145 , the 
genotype $(\mathrm{P}=0.046)$ and allele $(\mathrm{P}=0.021)$ were different in the groups. The frequencies for rs $2228145 \mathrm{C}$ minor allele (358Ala) were $34.7 \%(27-43 \%)$ and $44.0 \%(36-51 \%)$ for controls and T1D subjects, respectively. In conclusion, IL-6 rs1800795 was not associated with adult-onset T1D; however, IL-6R rs2228145 was associated with T1D development in adulthood, and carriers of the minor $\mathrm{C}$ allele are at increased risk for adult-onset $\mathrm{T} 1 \mathrm{D}(\mathrm{OR}=1.48$; $95 \% \mathrm{CI}=1.06-2.07)$.

Key words: Promoter polymorphism; $-174 \mathrm{G}>\mathrm{C}$; Adult-onset T1D; IL6R; Asp358Ala; Genetic susceptibility

\section{INTRODUCTION}

Type 1 diabetes (T1D) is a chronic autoimmune-mediated disease caused by death of pancreatic $\beta$ cells (Eisenbarth, 1986; Atkinson, 2014; Roep et al., 2019), and its incidence has increased in recent years (You and Henneberg, 2016). Genome-wide association studies (GWAS) have identified more than 60 susceptibility regions to T1D across the human genome, which are marked by single nucleotide polymorphisms (SNPs) (Ram and Morahan, 2017). Several non-HLA type 1 diabetes susceptibility genes have been demonstrated to influence disease progression, and it has been suggested that their contribution may be partly associated with the $\beta$-cell, in which several gene products have demonstrated expression in cytokine-stimulated islets (Eizirik et al., 2012).

Cytokine signals may be influenced by genetic background, and polymorphisms may determine their impact in T1D autoimmunity (Lee et al., 2015). Proinflammatory cytokines, such as TNF- $\alpha$, IL- $1 \beta$, IFN- $\gamma$, IL- $1 \alpha$, IL-6, and IL-18, have been implicated in the pathogenesis of T1D (Grunnet et al., 2009). Therefore, interleukins and interleukin receptor genes are among the genetic risk factors of T1D (Ram and Morahan, 2017).

Interleukin-6 (IL-6, Chr7, 7p15.3; OMIM 147620) plays a critical role in the immune response (Feigerlova and Battaglia-Hsu, 2017). It binds to an IL-6 membrane receptor (IL-6R, Chr1, 1q21.3; OMIM 147880) or soluble receptor (sIL-6R), and the complex IL-6-IL-6R or IL-6-sIL-6R couples with gp130 protein to trigger intracellular signaling (Mihara et al., 2012). The soluble sIL-6R is generated by shedding the membranebound form or by proteolytic cleavage of the ectodomain (Mullberg et al., 1994; Horiuchi et al., 1998; Hurst et al., 2001), which triggers trans-signaling (Rose-John, 2012). There is evidence that IL-6 trans-signaling possesses a prevalent pro-inflammatory role, whereas classic IL-6 signaling via the membrane bound IL-6R is needed for regenerative or antiinflammatory processes (Rose-John, 2012; Hodes et al., 2016).

Dysregulation of the IL-6/IL-6R system has been associated with the pathogenesis of several autoimmune and inflammatory diseases in humans (Tanaka and Kishimoto, 2012; Tanaka et al., 2014). In T1D, IL-6 signaling is a complex process. No difference between T1D and healthy subjects was identified; however, a putative post-translational regulation was suggested (Feigerlova and Battaglia-Hsu, 2017).

Several polymorphisms in and close to IL6 and to IL6R genes have been identified. There are studies investigating the genetic association between IL6 and IL-6R 
polymorphisms and type 1 diabetes, type 2 diabetes, insulin resistance, and other features of the metabolic syndrome (Fishman et al., 1998; Wang et al., 2005).

The IL-6 promoter $-174 \mathrm{G}>\mathrm{C}$ (rs1800795) polymorphism has been suggested to functionally affect IL6 promoter activity (Fishman et al., 1998). The rs1800795 G allele in homozygous (GG genotype) was associated with higher concentrations of IL-6 increasing the immune response (Larcombe et al., 2008; Nadeem et al., 2017).

IL-6R rs2228145 is located in exon 9, a putative extracellular cleavage, domain and the $\mathrm{A}>\mathrm{C}$ polymorphism promotes a non-synonymous change of aspartic acid to alanine in the position 358 (Asp358Ala; D358A) (Galicia et al., 2004). In vivo studies have shown higher concentrations of the IL-6R soluble form (dIL-6R) in carriers of the $\mathrm{C}$ allele (350Ala). However, polymorphism effects in diabetes are controversial (Ferreira et al., 2013).

Type 1 diabetes manifests predominantly at a young age (childhood onset) and less frequently in adults (adult onset). Both forms of T1D have shown differences based on genetic influences (Howson et al., 2012).

We examined the association between adult-onset T1D and the IL-6 promoter rs1800795 and IL-6R rs2228145 in a Euro-Brazilian population.

\section{MATERIAL AND METHODS}

\section{Ethical considerations}

The study was approved by the Ethics Committee of the Federal University of Paraná (CAAE 01038112.0.0000.0102). All subjects participating in the research provided written consent after being properly informed of the potential benefits and potential harm associated with the study.

\section{Subjects}

This cross-sectional study was conducted with Euro-Brazilian adults who attended the Clinical Hospital of the Federal University of Parana, Curitiba, Parana State, in Southern Brazil. Briefly, 291 unrelated adults were classified as healthy (control, $\mathrm{n}=150$ ) or as adultonset T1D diagnosed at age $\geq 18$ years (T1D, $n=141$ ) according to international guidelines (American Diabetes Association, 2019). Clinical and anthropometric data were obtained from all patients. The control group was obtained from blood bank donors. The groups were matched by sex and age.

\section{Genotyping}

DNA was extracted from peripheral blood leukocytes (buffy coat) by the "salting out" method of Lahiri and Nurnberger (1991). DNA samples with an A260/A280 absorbance ratio between 1.6 and 1.9 were used, and the concentrations of all samples were normalized to $100 \mathrm{ng} / \mu \mathrm{L}$ for polymerase chain reaction-restriction fragment length polymorphism (PCR-RFLP).

The rs 1800795 IL-6 and rs2228145 IL6-R were genotyped by PCR-RFLP. PCR was performed using the following primers: rs1800795F-5'-TTCCCCCTAGTTGTGTCTTGC- 
3', rs1800795 R-5'-TGGGGCTGATTGGAAACCT-3'; and rs2228145 F-5'CCTCTTCCTCCTCTATCTTCAATTTT-3'，R-5'- AATGTGGGCAGTGGTACTGAA-3' as described by Ruzzo et al. (2014). The amplification protocol for genomic DNA (final volume $20 \mu \mathrm{L}$ ) contained $100 \mathrm{ng}$ genomic DNA, 10 pmol each primer, $0.2 \mathrm{mM}$ dNTPs, $1.5 \mathrm{mM} \mathrm{MgCl}_{2}, 1.0 \mathrm{U}$ Taq DNA polymerase (Invitrogen, Carlsbad, CA, USA), and 1× reaction buffer (Invitrogen).

The PCR amplification protocol, for both polymorphisms, was started with an initial denaturation step at $95^{\circ} \mathrm{C}$ for $10 \mathrm{~min}$, followed by 35 cycles of denaturation at $95^{\circ} \mathrm{C}$ for $15 \mathrm{~s}$, annealing at $30^{\circ} \mathrm{C}$ for $30 \mathrm{~s}$, and extension at $72^{\circ} \mathrm{C}$ for $30 \mathrm{~s}$, with a final step at $72^{\circ} \mathrm{C}$ for $5 \mathrm{~min}$. The rs 1800795 IL-6 and rs2228145 IL6-R PCR products were digested with Hsp92 II and Hind III (Promega, Madison, WI, USA), respectively. Restriction fragments were resolved by $15 \%$ polyacrylamide gel $(29: 1)$ electrophoresis, stained with ethidium bromide $(0.5 \mu \mathrm{g} / \mathrm{mL})$ and photo-documented with L-PIX (Loccus Biotechnology, São Paulo, Brazil) using UV light $(302 \mathrm{~nm})$. The expected sizes of the fragments, as described by Ruzzo et al. (2014), for rs1800795 IL-6 were genotypes GG (75 bp), GC (75 bp + 50 bp $+25 \mathrm{bp}$ ), and CC (50 bp + $25 \mathrm{bp}$ ), and rs2228145 IL6-R were genotypes AA (73 bp), AC (73 bp $+43 b p+30 b p)$, and CC (43 bp +30 bp). PCR-RFLP showed clear genotype discrimination in all samples.

\section{Biochemical markers}

The biochemical parameters were measured using the Architect Ci 8200 automated system (Abbott Diagnostics, Lake Forest, IL, USA) or Labmax 400 (Labtest, Labtest, Inc., Delta, British Columbia, Canada) with reagents, calibrators, and controls from the equipment manufacturer. Glycated hemoglobin (HbA1c) was measured using immunoturbidimetry, and 1,5-anhydroglucitol was measured enzymatically (GlycoMark, Tomen America, New York, NY, USA) in an automated system (Labmax 400).

\section{Statistical analysis}

Continuous variables with normal distribution, verified by the KolmogorovSmirnov test, were compared by the two-tailed Student's $t$ test for independent variables. The Mann-Whitney U test was used to compare groups without normal distribution. The chi-square test was used to compare categorical variables. Hardy-Weinberg equilibrium and allele comparisons were calculated using the DeFinetti program (http://ihg.gsf.de/cgibin/hw/hwa1.pl). Further, 95\% confidence intervals (95\% CI), odds ratio (OR), and all statistical analysis were calculated with the MedCalc Statistical Software version 18.11.3 (MedCalc Software bvba, Ostend, Belgium). A P-value of less than 5\% (P<0.05) was considered significant.

\section{RESULTS}

Clinical data of the study group are shown in Table 1 . The groups were matched by age and gender. The age at diagnosis in the T1D group was between 18 and 38 years (adult onset T1D). T1D subjects were determined to be leaner than control subjects, as assessed by 
body mass index. The average time of diabetes was 14 years, and $69.2 \%$ had a family history of diabetes.

As expected, the glycemia concentration in the T1D group was significantly higher ( $\mathrm{P}<0.001)$ when compared to the healthy controls, which shows consistency in the sample classification. Furthermore, glycemic biomarkers were statistically different between groups (Table 2). From the results obtained, we observed inadequate glycemic control in the T1D group (poor glycemic control criteria: fasting glycemia $>7.2 \mathrm{mmol} / \mathrm{L}, \mathrm{HbA} 1 \mathrm{c}>7 \%$, and 1,5AG <61 $\mu \mathrm{mol} / \mathrm{L}$ ) (Van Leeuwen and Bladh, 2015; SBD, 2017; ADA, 2019).

Table 1. Anthropometric and clinical parameters for adult-onset Type 1 diabetes (T1D) patients and healthy controls.

\begin{tabular}{lccl}
\hline Parameters & Control $(\mathbf{n}=\mathbf{1 5 0})$ & T1D $(\mathbf{n}=\mathbf{1 4 1})$ & P \\
\hline Age, years & $44(40-49)$ & $45(34-52)$ & $0.602^{*}$ \\
Male/Female, $\mathrm{n}$ & $53 / 97$ & $48 / 93$ & $0.817^{* *}$ \\
Weight $(\mathrm{kg})$ & $74(64-83)$ & $68(60-82)$ & $0.016^{*}$ \\
Height $(\mathrm{cm})$ & $166.2 \pm 8.9$ & $163.3 \pm 9.8$ & 0.009 \\
BMI $\left(\mathrm{kg} / \mathrm{m}^{2}\right)$ & $27.0 \pm 4.2$ & $25.8 \pm 4.3$ & 0.018 \\
Duration of diabetes, years & NA & $14.8 \pm 10.8$ & - \\
Family history of diabetes $\%$ & NA & $69.2 \%$ & - \\
\hline
\end{tabular}

Control, healthy subjects; BMI, body mass index. Values are mean \pm SD or median (interquartile range). NA, Not Applicable. P-value, Independent Student $t$ test (two-tailed), *Mann-Whitney $\mathrm{U}$ test, or ** chi-square test. P values in bold are significant $(\mathrm{P}<0.05)$.

Serum concentrations of albumin and total proteins showed no evidence of malnutrition or protein loss. The highly significant concentrations of both markers in the T1D group could be associated with minor dehydration associated with polyuria in T1D subjects.

The concentrations of kidney function biomarkers, creatinine and urea, were in the reference range, suggesting no renal damage in the T1D group (Ceriotti et al., 2008). The highly significant concentration of these biomarkers in T1D compared with healthy subjects could be associated with hydrodynamic changes, as expected in this pathology.

Table 2. Concentrations of biochemical parameters in adult-onset type 1 diabetics (T1D) and healthy controls.

\begin{tabular}{lccc}
\hline Parameters & Control $(\mathbf{n}=\mathbf{1 5 0})$ & T1D $(\mathbf{n}=\mathbf{1 4 1})$ & P \\
\hline Glycemia $(\mathrm{mmol} / \mathrm{L})$ & $5.3(4.6-5.8)$ & $9.5(5.8-13.8)$ & $<0.001$ \\
$\mathrm{HbA1c}(\%)$ & $5.4(5.2-5.6)$ & $8.8(7.6-9.7)$ & $<0.001$ \\
$\mathrm{HbA1c}(\mathrm{mmol} / \mathrm{mol})$ & $36(33-38)$ & $73(60-83)$ & $<0.001$ \\
$1,5-\mathrm{AG}(\mu \mathrm{mol} / \mathrm{L})$ & $108(102-114)$ & $4.1(2.3-5.9)$ & $<0.001$ \\
Total protein $(\mathrm{g} / \mathrm{L})$ & $69(66-72)$ & $82(74-88)$ & $<0.001$ \\
Albumin $(\mathrm{g} / \mathrm{L})$ & $39(38-40)$ & $41(38-43)$ & $<0.001$ \\
Creatinine $(\mu \mathrm{mol} / \mathrm{L})$ & $49.5(42.4-59.2)$ & $72.4(70.7-88.4)$ & $<0.001$ \\
Urea $(\mathrm{mmol} / \mathrm{L})$ & $3.8(3.3-4.4)$ & $5.3(4.1-6.4)$ & \\
Controls, healthy subjects. Values are medians (interquartile range, $\left.25^{\text {th }}-75^{\text {th }}\right) . \mathrm{ND}$, no information available. P-values \\
are Mann-Whitney U test. P-values in bold are significant $(\mathrm{P}<0.05)$.
\end{tabular}

Genotypes and allele frequencies of the polymorphisms were in Hardy-Weinberg equilibrium $(\mathrm{P}<0.05$; Table 3). The genotypic and allelic frequencies of the rs1800795 
polymorphism did not differ between the study groups. The rs 1800795 polymorphism of the $I L-6 R$ gene showed an association with T1D, with significant differences between the genotypic and allelic frequencies between the study groups and in the dominant model. The minor frequency $\mathrm{C}$ allele was associated with a higher risk for T1D, with an odds ratio of 1.48 (95\% CI 1.06 - 2.07) calculated for the allele frequency.

Table 3. Genotypic and allelic frequencies of $I L-6$ rs1800795 and $I L-6 R$ rs8182284 in adult-onset type 1 diabetics (T1D) and healthy controls.

\begin{tabular}{lllll}
\hline Polymorphism & & Control $(\mathbf{n}=\mathbf{1 5 0})$ & T1D $(\mathbf{n}=\mathbf{1 4 1})$ & P \\
\hline (rs1800795) & G/G & $75(50.0)$ & $63(44.7)$ & 0.599 \\
G $>$ C & G/C & $68(45.3)$ & $69(48.9)$ & \\
$I L-6$ & C/C & $7(4.7)$ & $9(6.4)$ & 0.350 \\
MAF & C & 27.3 & 30.1 & \\
{$[95 \%$ IC] } & & {$[20-35]$} & $723-38]$ & 0.749 \\
Dominant & GC+CC vs GG & $75 / 75$ & $78 / 63$ & 0.521 \\
Recessive & CC vs GC+GG & $7 / 142$ & $9 / 132$ & 0.046 \\
(rs2228145) & A/A & $59(39.3)$ & $39(27.7)$ & \\
A C & A/C & $78(52.0)$ & $80(56.7)$ & \\
$I L-6 R$ & C/C & $13(8.7)$ & $22(15.6)$ & 0.021 \\
MAF & C & 34.7 & 44.0 & \\
{$[95 \%$ CI $]$} & & {$[27-43]$} & {$[36-51]$} & 0.035 \\
Dominant & AC+CC vs AA & $91 / 59$ & $102 / 39$ & 0.069 \\
Recessive & CC vs AA+AC & $13 / 137$ & $22 / 119$ & \\
\hline
\end{tabular}

Controls, healthy subjects. Values were n (\%); MAF, minor allele frequencies; 95\% CI, 95\% confidence interval; $P$, probability, chi-square test. Hardy-Weinberg equilibrium (P-value) in healthy controls and T1D for rs1800795 (0.084; $0.081)$ and rs $2228145(0.070 ; 0.072)$. Dominant model (others vs. prevalent homozygous genotype) and recessive model (rare homozygous genotype vs. others). Odds ratios (95\% Confidence Interval) for rs $2228145 \mathrm{C}$ allele frequencies and dominant model (AA genotype) were $1.48(1.06-2.07)$ and $0.59(0.36-0.97)$, respectively.

We associated the polymorphic genotypes with anthropometric data and several common serum biomarkers for glycemic control (fasting plasma glucose, HbA1c, and 1,5AG), renal function (urea and creatinine), and proteins (total protein and albumin), applying regression analysis. Our observations did not show any association between the study polymorphisms and the factors mentioned above in both studied groups (data not shown).

\section{DISCUSSION}

Interleukin 6 (IL-6) is a multifunctional cytokine that is involved in inflammatory and autoimmune diseases (Hundhausen et al., 2016). IL-6 is a pleiotropic cytokine with a number of important biological activities, including regulation of acute-phase reactions and generation of immune responses (Duncan and Berman, 1991). IL-6 has also been shown to have an essential role in the pathogenesis of islet $\beta$ cell destruction in animal models (Campbell et al., 1991). IL-6 levels and actions are mainly controlled by sIL-6R, and several studies have shown increased sIL6R levels in different autoimmune diseases (Marinou et al., 2010; Eleftherohorinou et al., 2011).

Hundhausen et al. (2016) described IL-6 signaling increases in some individuals with T1D, presumably favored by metabolic, immunological, or perhaps genetic mechanisms. 
There is evidence that the activity levels of IL-6 and its receptor are regulated by functional polymorphisms in corresponding genes (Smith and Humphries, 2009). Consequently, these polymorphisms may contribute to the genetic background of T1D by modifying amplification of the immune response (Ferreira et al., 2013; Woo and Humphries, 2013).

Carriers of genetic variants that up-regulate IL-6 and sIL-6R secretion may represent patient sub-groups with host-related features that favor T1D. Notably, we found that the minor C allele of the IL-6R variant (rs2228145) showed an association with T1D. Carriers of the $\mathrm{C}$ allele showed 1.48-fold more susceptibility to T1D. This result is contradictory to that obtained by Ferreira et al. (2013), which found an association of the C allele with protection from T1D (OR 0.94; 0.91 - 0.99). However, these authors discuss that the protective effect seems to be a paradox, as the $\mathrm{C}$ allele was associated with higher circulating soluble forms of the IL-6 receptor (sIL-6R) (Reich et al., 2007; Ferreira et al., 2013) and IL-6 levels (Reich et al., 2007; IL6R Genetics Consortium Emerging Risk Factors Collaboration et al., 2012; Naitza et al., 2012).

However, the $\mathrm{C}$ allele results in nearly a 2 -fold increase in sIL-6R levels in homozygous carriers of the SNP rs2228145 (Garbers et al., 2014). These authors demonstrated that these individuals were protected from a number of inflammatory diseases, including coronary heart disease and rheumatoid arthritis (Ferreira et al., 2013). It has been suggested that this finding can be explained by the increased capacity of sIL6R/gp130 to buffer for IL-6 in the blood of SNP rs2228145 carriers (Scheller and RoseJohn, 2012).

The functional $\mathrm{C}$ allele impairs classical IL-6 receptor signaling, which is considered to have homeostatic and anti-inflammatory effects, and IL-6 trans-signaling mainly regulates pro-inflammatory reactions (Rose-John, 2017). Similarly, IL-6 transsignaling via the sIL-6R has the potential to lead to stronger and longer intracellular signaling than classic IL-6 signaling via the membrane-bound IL-6R (Rose-John, 2012).

Notably, T1D patients studied by Ferreira et al. (2013) were under 17 years of age at diagnosis (childhood onset), while our study was composed of subjects with T1D diagnosis of $\geq 18$ years (adult onset). Similar effects have been reported by other cytokines (IL-10); however, polymorphisms modulate the degree of islet destruction and the age-atonset of type 1 diabetes, suggesting that variability of the age-at-onset of this disease is genetically determined (Ide et al., 2002). Others studies conducted with juvenile onset of T1D imply that IL-6 genotypic variants may influence the time of disease onset or modulate the risk of diabetes development (Jahromi et al., 2000; Gillespie et al., 2005; Hermann et al., 2005).

These results are different from our findings where no association was identified between IL-6 -174G>C (rs1800795) and adult-onset T1D in the present study. Similarly, Tsiavou et al. (2004) did not find an association of IL-6 -174G $>$ C (rs1800795) with LADA (Latent Autoimmune Diabetes of the Adult). Additionally, some studies suggest that the 174GG genotype is protective against early T1D onset; however, this protection may be lost later in life (Jahromi et al., 2000; Gillespie et al., 2005; Hermann et al., 2005; Mysliwska et al., 2009).

Frequencies of the rare $\mathrm{C}$ allele of IL-6 -174G $>\mathrm{C}$ (rs1800795) found in this study for the control $(27.3 \%, 95 \%$ CI $20-35 \%)$ and T1D groups $(30.1,95 \%$ CI $23-38 \%)$ were lower than that reported for other Caucasian populations, such as British (control $42.6 \%$ and 
T1D 44.0\%) (Cooper et al., 2007), Greeks (control 35.9\%) (Tsiavou et al., 2004), Polish (control 50.0\% and T1D 58.8\%) (Mysliwska et al., 2009), and Slovaks (control 38.6\% and T1D 48.7\%) (Javor et al., 2010).

The frequency of the minor C allele of IL-6R Asp358Ala (rs2228145) found in this study for the control $(34.7 \%$, 95\% IC 27 - 43) was similar to Americans (39.6\%) (Qi, Rifai and Hu, 2007), Spanish (39.3\%) (Cenit et al., 2012), Polish (33.2\%) (Kapelski et al., 2015) and lower than in Korean (44.5\%) (Kim et al., 2004) populations. We have not found information about this polymorphism in T1D.

There are many examples in the literature, suggesting that relevant analyses in different patient populations with complex diseases result in controversial data due to geneenvironment/gene-gene interactions or their different racial/ethnic origins and overall genetic composition (Howson et al., 2012). It is important to highlight this is a prospective study. Therefore, future studies with larger sample sizes will be required to confirm our findings.

In conclusion, IL-6 rs1800795 was not associated with adult-onset T1D. However, IL-6R rs2228145 was associated with T1D development in adulthood, and carriers of the minor $\mathrm{C}$ allele are at increased risk for adult-onset $\mathrm{T} 1 \mathrm{D}(\mathrm{OR}=1.48 ; 95 \% \mathrm{CI}=1.06-2.07)$.

\section{ACKNOWLEDGMENTS}

This study was funded by the government agencies CNPq (National Council for Scientific and Technological Development), Araucaria Foundation, and the Coordenação de Aperfeiçoamento de Pessoal de Nível Superior - Brasil (CAPES) - Finance Code 001.

\section{CONFLICTS OF INTEREST}

The authors declare no conflict of interest.

\section{REFERENCES}

American Diabetes Association (2019). Classification and Diagnosis of Diabetes: Standards of Medical Care in Diabetes-2019. Diabetes Care. 42: S13-S28.

Atkinson MA, Eisenbarth GS and Michels AW (2014). Type 1 diabetes. Lancet. 383: 69-82.

Campbell IL, Kay TW, Oxbrow L and Harrison LC (1991). Essential role for interferon-gamma and interleukin-6 in autoimmune insulin-dependent diabetes in NOD/Wehi mice. J. Clin. Invest. 87: 739-742.

Cenit MC, Simeon CP, Fonollosa V, Espinosa G, et al. (2012). No evidence of association between functional polymorphisms located with in IL6R and IL6ST genes and systemic sclerosis. Tissue Antigens. 80: 254-258.

Ceriotti F, Boyd JC, Klein G, Henny J, et al. (2008). Reference intervals for serum creatinine concentrations: assessment of available data for global application. Clin. Chem. 54: 559-566.

Cooper JD, Smyth DJ, Bailey R, Payne F, et al. (2007). The candidate genes TAF5L, TCF7, PDCD1, IL6 and ICAM1 cannot be excluded from having effects in type 1 diabetes. BMC Med. Genet. 8: 71.

Duncan MR and Berman B (1991). Stimulation of collagen and glycosaminoglycan production in cultured human adult dermal fibroblasts by recombinant human interleukin 6. J. Invest. Dermatol. 97: 686-692.

Eizirik DL, Sammeth M, Bouckenooghe T, Bottu G, et al. (2012). The human pancreatic islet transcriptome: expression of candidate genes for type 1 diabetes and the impact of pro-inflammatory cytokines. PLoS Genet. 8: e1002552.

Eleftherohorinou H, Hoggart CJ, Wright V, Levin M, et al. (2011). Pathway-driven gene stability selection of two rheumatoid arthritis GWAS identifies and validates new susceptibility genes in receptor mediated signalling pathways. Hum. Mol. Genet. 20: 3494-3506.

Feigerlova E and Battaglia-Hsu SF (2017). IL-6 signaling in diabetic nephropathy: From pathophysiology to therapeutic perspectives. Cytokine Growth Factor Rev. 37: 57-65. 
Ferreira RC, Freitag DF, Cutler AJ, Howsin JM, et al. (2013). Functional IL6R 358Ala allele impairs classical IL-6 receptor signaling and influences risk of diverse inflammatory diseases. PLoS Genet. 9: e1003444.

Fishman D, Faulds G, Jeffery R, Mohamed-Ali V, et al. (1998). The effect of novel polymorphisms in the interleukin-6 (IL-6) gene on IL-6 transcription and plasma IL-6 levels, and an association with systemic-onset juvenile chronic arthritis. J. Clin. Invest. 102: 1369-1376.

Galicia JC, Tai H, Komatsu Y, Shimada Y, et al. (2004). Polymorphisms in the IL-6 receptor (IL-6R) gene: strong evidence that serum levels of soluble IL-6R are genetically influenced. Genes Immun. 5: 513-516.

Garbers G, Monhasery N, Aparicio-Siegmund S, Lokau J, et al. (2014). The interleukin-6 receptor Asp358Ala single nucleotide polymorphism rs2228145 confers increased proteolytic conversion rates by ADAM proteases. Biochim Biophys Acta. 1842: 1485-1494.

Gillespie KM, Nolsoe R, Betin VM, Kristiansen OP, et al. (2005). Is puberty an accelerator of type 1 diabetes in IL6174CC females? Diabetes. 54: 1245-1248.

Grunnet LG, Aikin R, Tonnesen MF, Paraskevas S, et al. (2009). Proinflammatory cytokines activate the intrinsic apoptotic pathway in beta-cells. Diabetes. 58: 1807-1815.

Hermann C, Krikovszky D, Fust G, Kovacs M, et al. (2005). Association between interleukin-6 polymorphism and ageat-onset of type 1 diabetes. Epistatic influences of the tumor necrosis factor-alpha and interleukin-1beta polymorphisms. Eur Cytokine Netw. 16: 277-281.

Hodes GE, Menard C and Russo SJ (2016). Integrating Interleukin-6 into depression diagnosis and treatment. Neurobiol. Stress. 4: 15-22.

Horiuchi S, Ampofo W, Koyanagi Y, Yamashita A, et al. (1998). High-level production of alternatively spliced soluble interleukin-6 receptor in serum of patients with adult T-cell leukaemia/HTLV-I-associated myelopathy. Immunology. 95: 360-369.

Howson JM, Cooper JD, Smyth DJ, Walker NM, et al. (2012). Evidence of gene-gene interaction and age-at-diagnosis effects in type 1 diabetes. Diabetes. 61: 3012-3017.

Hundhausen C, Roth A, Whalen E, Chen J, et al. (2016). Enhanced T cell responses to IL-6 in type 1 diabetes are associated with early clinical disease and increased IL-6 receptor expression. Sci. Transl. Med. 8: 356ra119

Hurst SM, Wilkinson TS, McLoughlin RM, Jones S, et al. (2001). IL-6 and its soluble receptor orchestrate a temporal switch in the pattern of leukocyte recruitment seen during acute inflammation. Immunity. 14: 705-714.

Ide A, Kawasaki E, Abiru N, Sun F, et al. (2002). Genetic association between interleukin-10 gene promoter region polymorphisms and type 1 diabetes age-at-onset. Hum. Immunol. 63: 690-695.

IL6R Genetics Consortium Emerging Risk Factors Collaboration, Sarwar N, Butterworth AS, Freitag DF et al. (2012). Interleukin-6 receptor pathways in coronary heart disease: a collaborative meta-analysis of 82 studies. Lancet. 379: 1205-1213.

Jahromi MM, Millward BA and Demaine AG (2000). A polymorphism in the promoter region of the gene for interleukin-6 is associated with susceptibility to type 1 diabetes mellitus. J. Interferon. Cytokine Res. 20: 885-888.

Javor J, Ferencik S, Bucova M, Stuchlikova M, et al. (2010). Polymorphisms in the genes encoding TGF-beta1, TNFalpha, and IL-6 show association with type 1 diabetes mellitus in the Slovak population. Arch. Immunol. Ther. Exp. 58: 385-393.

Kapelski P, Skibinska M, Maciukiewicz M, Wilkosc M, et al. (2015). Association study of functional polymorphisms in interleukins and interleukin receptors genes: IL1A, IL1B, IL1RN, IL6, IL6R, IL10, IL10RA and TGFB1 in schizophrenia in Polish population. Schizophr. Res. 169: 1-9.

Kim HJ, Higashimori T, Park SY, Choi H, et al. (2004). Differential effects of interleukin-6 and -10 on skeletal muscle and liver insulin action in vivo. Diabetes. 53: 1060-1067.

Lahiri DK and Nurnberger JI (1991). A rapid non-enzymatic method for the preparation of HMW DNA from blood for RFLP studies. Nucleic Acids Res. 19: 5444.

Larcombe LA, Orr PH, Lodge AM, Brown JS, et al. (2008). Functional gene polymorphisms in canadian aboriginal populations with high rates of tuberculosis. J. Infect Dis. 198: 1175-1179.

Lee YH, Kim JH and Song GG (2015). Interleukin-18 promoter -607 C/A and -137 G/C polymorphisms and susceptibility to type 1 diabetes: A meta-analysis. Hum. Immunol. 76: 537-545.

Marinou I, Walters K, Windfield J, Bax DE, et al. (2010). A gain of function polymorphism in the interleukin 6 receptor influences RA susceptibility. Ann. Rheum Dis. 69: 1191-1194.

Mihara M, Hashizume M, Suzuki M, et al. (2012). IL-6/IL-6 receptor system and its role in physiological and pathological conditions. Clin. Sci. (Lond). 122: 143-159.

Mullberg J, Oberthur W, Lottspeich F, Mehl E, et al. (1994). The soluble human IL-6 receptor. Mutational characterization of the proteolytic cleavage site. J. Immunol. 152: 4958-4968.

Mysliwska J, Zorena K, Mysliwiec M, Malinowska E, et al. (2009). The -174GG interleukin-6 genotype is protective from retinopathy and nephropathy in juvenile onset type 1 diabetes mellitus. Pediatr. Res. 66: 341-345.

Nadeem A, Mumtaz S, Naveed AK, Mansoor Q, et al. (2017). Association of IL-6 C-174G (rs 1800795) single nucleotide polymorphism with type 2 diabetes mellitus in Pakistani population. J. Pak. Med. Assoc. 67: 428-433.

Naitza S, Porcu E, Steri M, Taub DD, et al. (2012). A genome-wide association scan on the levels of markers of inflammation in Sardinians reveals associations that underpin its complex regulation. PLoS Genet. 8: e1002480.

Genetics and Molecular Research 18 (3): gmr18260 
Qi L, Rifai N and Hu FB (2007). Interleukin-6 receptor gene variations, plasma interleukin-6 levels, and type 2 diabetes in U.S. Women. Diabetes. 56: 3075-3081.

Ram R and Morahan G (2017). Effects of Type 1 Diabetes Risk Alleles on Immune Cell Gene Expression. Genes (Basel). 8.

Reich D, Patterson N, Ramesh V, Jager PL, et al. (2007). Admixture mapping of an allele affecting interleukin 6 soluble receptor and interleukin 6 levels. Am. J. Hum. Genet. 80: 716-726.

Rose-John S (2012). IL-6 trans-signaling via the soluble IL-6 receptor: importance for the pro-inflammatory activities of IL-6. Int. J. Biol. Sci. 8: 1237-1247.

Rose-John S (2017). The Soluble Interleukin 6 Receptor: Advanced Therapeutic Options in Inflammation. Clin. Pharmacol. Ther. 102: 591-598.

Ruzzo A, Catalano V, Canestrari E, Giacomini E, et al. (2014). Genetic modulation of the interleukin 6 (IL-6) system in patients with advanced gastric cancer: a background for an alternative target therapy. BMC Cancer. 14: 357.

Scheller J and Rose-John S (2012). The interleukin 6 pathway and atherosclerosis. Lancet. 380: 338.

Sherr JL, Hermann JM, Campbell F, Foster NC, et al. (2016). Use of insulin pump therapy in children and adolescents with type 1 diabetes and its impact on metabolic control: comparison of results from three large, transatlantic paediatric registries. Diabetologia. 59: 87-91.

Smith AJ and Humphries SE (2009). Cytokine and cytokine receptor gene polymorphisms and their functionality. Cytokine Growth Factor Rev. 20: 43-59.

Sociedade Brasileira de Diabetes (2017). Diretrizes da Sociedade Brasileira de Diabetes 2017-2018. Clannad.

Swerdlow DI, Holmes MV, Kuchenbaecker KB, et al. (2012). The interleukin-6 receptor as a target for prevention of coronary heart disease: a mendelian randomisation analysis. Lancet. 379: 1214-1224.

Tanaka T and Kishimoto T (2012). Targeting interleukin-6: all the way to treat autoimmune and inflammatory diseases. Int. J. Biol. Sci. 8: 1227-1236.

Tanaka T, Narazaki M and Kishimoto T (2014). IL-6 in inflammation, immunity, and disease. Cold Spring Harb. Perspect. Biol. 6: a016295.

Tsiavoi A, Hatziagelaki E, Chaidaroglou A, Manginas A, et al. (2004). TNF-alpha, TGF-beta1, IL-10, IL-6, gene polymorphisms in latent autoimmune diabetes of adults (LADA) and type 2 diabetes mellitus. J. Clin. Immunol. 24: 591-599.

Van Leeuwen AM and Bladh ML (2015). Davis's comprehensive handbook of laboratory diagnostic tests with nursing implications. Davis Company. 6: 1574-1595.

Wang MC, Bohmann D and Jasper H (2005). JNK extends life span and limits growth by antagonizing cellular and organism-wide responses to insulin signaling. Cell. 121: 115-125.

Woo P and Humphries SE (2013). IL-6 polymorphisms: a useful genetic tool for inflammation research? J. Clin. Invest. 123: 1413-1414.

You WP and Henneberg M (2016). Type 1 diabetes prevalence increasing globally and regionally: the role of natural selection and life expectancy at birth. BMJ. Open Diabetes Res. Care. 4: e000161. 